\title{
Review of Energy Efficiency and System Performance of Residential Heat Pump Water Heaters
}

\begin{abstract}
Energy efficiency is an essential component of water heating considerations in the overall efforts to achieve national energy saving goals. Although heat pump water heaters have been around for over three decades, this technology has only matured in recent years, in part because of improved systems and infrastructure as well as emerging energy conservation standards on water heating. The goal of this study is to provide a comprehensive and in-depth review of heat pump water heater research on system energy efficiency and performance topics. The study focuses on laboratory and field (in-situ) experiments and measurements, modeling of energy use and efficiency, technological modifications or upgrades, and control operation strategies; with emphasis on the Coefficient of Performance (COP), reliability, and energy savings. The review shows that while most of current heat pump water heater systems operate in the COP range of 1.8-2.5, there are some potential technological updates that could augment the current systems and increase COP to a range of 2.8-5.5. Issues that could dampen the adoption of these technologies are discussed. The review identified key areas for future studies that are still lacking in support of various changes suggested for increasing heat pump water heaters efficiency and performance.
\end{abstract}

\section{Keywords}

Air Sourced Heat Pump Water Heater; Coefficient of Performance; Energy Use; Operation Optimization; System Reliability 


\section{Introduction}

Water heating represents approximately $18 \%$ of the energy consumed in U.S. homes, according to the 2009 Residential Energy Consumption Survey (RECS) [1]. This is the third highest energy end use, following space heating (42\%) and combined appliances, electronics, and lighting (35\%). In 2009 alone, the total annual energy consumed for water heating by 47 million households in the U.S. that are using electric resistance water heater was estimated to be close to one quadrillion Btu [1]. Therefore, reducing energy use for water heating can substantially reduce national energy use. Current technology that is wildly used for water heating in homes, i.e. the electric resistance system, has reached the maximum potential of thermodynamic cycles. Therefore, a more efficient energy delivery system is needed. Incorporating heat pump technology to replace the standard electric water heating system has been widely considered and proven an economically feasible and technologically advance alternative.

The heat pump designs, which are commonly used for space cooling or heating application, efficiently transfer heat from the surrounding air (or other renewable sources) to the water, instead of using energy primarily to heat water directly. As a result, integrating a heat pump design with an electric water heater could increase the overall water heater efficiency significantly depending on the choice of heat pump technologies. Current generation of heat pump water heaters (HPWHs) reportedly offers efficiencies that are at least twice that of conventional electric water heaters in the U.S [1]. Correspondingly, the electrical demand of currently available HPWHs is typically one half that of conventional electric water heaters [2]. Another benefit of HPWHs is that the application of heat pump system also reduces environmental impact by lowering carbon emissions compared to conventional electric water heaters [2]. However, the environmental burden is still considerably higher than other fuel alternatives such as natural gas or propane, particularly when considering manufacture and emission of the fluorocarbon refrigerant $[3,4]$.

\subsection{History of HPWHs Development}

Historically, the potential of integrating heat pump in water heating systems has been recognized in the United States for over 70 years. Heat pump system was developed as a water heating system by Wilkes and Reed in the 1930s, several years after heat pump for heating and cooling that uses vapor compression cycle was invented and patented by Haldane in 1927 based on concepts introduced by William Thomson (also known as Lord Kelvin) [5]. Wilkes and Reed patented the first HPWH in 1937 [6]. Since then there had been a series of U.S. 
patents for HPWHs and its components, such as defrosting method [7], application for water heating and room cooling [8], and add-on "remote" heat pump system [9]. The industry began to manufacture domestic HPWH for the market in the 1950s [10]. However, the high production cost and sales tax, as well as falling electricity price dampened the production and development of HPWH. In the 1970s, because of the energy crisis, interest in HPWHs was again renewed. During this period, the National Rural Electric Cooperative Association (NRECA) and U.S. Department of Energy (DOE) developed a prototype HPWH [11] and mass-produced 100 units for field-testing by 20 utilities [12-14]. Of the 100 units tested, the utilities successfully completed testing for at least 25 months for 85 integrated HPWH units. The study assessed the performance, reliability, and impact on heating/cooling load. Issues with poor workmanship and installation, transportation damage; and design of the system emerged from the field-testing. The utility companies evaluated the HPWHs either during electric element operation or in a heat pump mode. Using data from this field evaluation, researchers calculated the efficiency of the HPWHs as the ratio of energy consumed with electric element operation to energy used in heat pump operation mode. They reported an average efficiency of 1.93 and average operating cost savings of $48 \%$ when comparing the heat pump mode and electric element operation. The study showed that energy savings could be realized, although various "design-fabrication-handling” problems still needed to be resolved. Another large-scale field study involving 45 utility tests of 278 HPWHs also obtained an average efficiency factor of approximately 2.0 or a $50 \%$ energy savings [15].

With the premise of substantial energy savings, HPWH manufacturing and sales rose significantly in the early 1980s but soon declined because of problems related to high production and installation costs, technical failures, excessive fan noise, and the lack of customer awareness. The decline was evident from the lack of growth in the industry during this period. There were 17 manufacturing companies in the early 1980s [14] and by mid 1990s there were only two left, with sales reduced from 10,000 to 2,000 units per year [16]. Following the decline in sales and production, researchers studied the issues affecting HPWHs and a new "market-optimized" HPWH prototype was developed and field-tested [17]. Based on the first field test in 16 cities, this prototype was able to maintain average field efficiency or commonly termed as coefficient of performance (COP) of 2.00 (range: 1.57-2.44) [18]. The study also identified some principle drivers for successful market penetration of HPWHs as follows: reliable operation, demonstration of life cycle savings, product warranty, and price reduction. Another field test of the same prototype in 19 occupied homes in California, however, obtained lower average COP of 1.31 (range: 0.89-1.88) [19]. The field tests uncovered practical installation issues, control system/board failures, thermostat and heating element failures, refrigerant leak, and wear on the compressor's crank pins and crankpin bushings. These issues show that the new prototype did not achieve the initial goal of balancing between 
cost and performance to meet market needs while addressing the issues plaguing the HPWH systems from earlier period.

HPWHs have remained in the background until, more recently, regulatory framework propelled it to the forefront of energy efficient water heating products [20]. Interest in HPWHs has never been as great as it is today. Several new studies support the reemergence of HPWHs. These studies show that new generations of HPWHs are promising with relatively high efficiency even when installed in unfavorable conditions such as unfinished basement in colder climate; and are more reliable in terms of performance and durability $[1,21]$. Additionally, HPWHs have been recommended as product with clean-electricity benefits [22]. Furthermore, recent efforts to improve HPWH systems and address the infrastructure concerns, both in the United States and in other countries, are making this system an increasingly viable solution for reducing water heating energy use [1]. In tandem with these improvements is the new momentum that HPWH gained in the water heater energy conservation standard, which requires that all electric resistance water heaters with tank sizes larger than 55 gallons to have a minimum energy factors of 2.0 [23]. This regulation is expected to substantially increase the market share of HPWHs in various sectors, particularly residential, and has resulted in the introduction of a new generation of HPWHs as niche water heating option in the U.S. market.

\subsection{Past HPWHs Technology Reviews}

Few review studies have been conducted to obtain a holistic understanding of the new generation HPWHs and associated system efficiency and performance issues. Available reviews have generally considered HPWHs as part of large pool water heating options in the market. Other reviews have considered heat pump for water heating among other common and large-scale applications. One of the most recent reviews discusses HPWHs as part of six categories of water heaters (the other five categories are wood, oil/gas, electric, solar, and instantaneous water heaters) [24]. A section of this review discusses the principle, advantages, and disadvantages of HPWHs; and the state-of-the-art information of air-source, geothermal, and solar heat pump water heaters. A group of researchers conducted a review on air-source and geothermal heat pump water heaters as part of a wider assessment on the potential of HPWHs application in the United Kingdom [25].

Technological feasibility, practical cost and site considerations, and climate effects are among the main factors discussed in the review. Another review on HPWHs discussed the technology developments, followed by modeling of the system components using energy and exergy ${ }^{1}$ analysis methods [26]. The review summarizes

\footnotetext{
${ }^{1}$ Exergy is defined as the maximum outputs that can be obtained from a system.
} 
the design, operational characteristics, and performance parameters of different types of HPWHs as reported from laboratory experiments and measurements.

\subsection{Objectives}

The main objective of this study is to review various technologies or approaches applied and tested on residential HPWHs - specifically the air-source type - in the laboratory experiments or field studies. The review focuses on how these technologies or new approaches affects system performance, reliability, or users' perception. The first part of this review identifies the areas of technological advancements or improvements of air-source HPWHs and elaborates their impacts on system performance and efficiency. The second part discusses the energy use and energy savings aspects, and the final part summarizes the impacts on or issues related to systems reliability.

\section{Methods}

The scope of our literature search included journal articles, technical reports and thesis/dissertations worldwide. We used various search engines — including but not limited to Sciencedirect, Jstor, Ebsco, Wiley, and Googlescholar ${ }^{2}$. We develop a list of keywords to obtain the most comprehensive publications of interest. We systematically entered each keyword and combination of keywords in the search engines. We then compiled relevant articles, papers, and reports and removed any duplication in the list. After a preliminary screening process to determine the suitability or relevancy of the papers based on titles and abstracts, we shortlisted 377

literatures published between 1987 and 2015 for further review. Subsequently, we categorized these papers by design types and technologies that contribute to improving efficiency and performance. We reviewed the publications in details to learn more about the objectives of each study and its main results. We summarized and recorded the review outcomes systematically and subsequently determined if there is sufficient information for inclusion in this review paper. Upon detailed review, seven papers were considered repeated from similar publications and studies and are therefore not listed as references. The complete review process yielded a final list of 102 literatures, which are presented and discussed in the following sections.

\section{Current HPWH Technology and Operating Characteristics}

A HPWH has three major components: a heat pump, consisting of a compressor, an evaporator, a condenser, and an expansion valve; two backup electric elements, usually in the range of 2,500-4,500 Watts; and a sizeable storage water tank wrapped in insulating materials. HPWHs use the concept of vapor compression cycle to

\footnotetext{
${ }^{2}$ See appendix for detailed information
} 
extract heat from its surrounding air and transfer that heat to cold water stored in a tank. This principle is what governs air conditioner operations but in reverse, or similar to refrigerators where extracted heat is released to the room. In the heat pump, liquid refrigerant flowing in a closed circuit is continuously compressed and expanded, during which heat from the air is absorbed and transferred to water in the tank. The additional backup electric elements are designed only to operate when the tank is nearly depleted of hot water, the minimum ambient conditions are not met, or the heat pump system fails. When a HPWH extracts heat from the air, the moisture in that air condenses, assuming the relative humidity in the room is high enough. That condensate is then drained away from the HPWH. Thus, a HPWH can also be used to provide additional space cooling and dehumidification. There are various types of HPWHs depending on its energy sources. Among the most common types are air-source, geothermal, and solar HPWHs, with air-source HPWHs generally considered most popular because of its lower initial costs and ease of maintenance compared to other types.

One of the earliest HPWH patents on record shows the use of the same HPWH components compared to current designs, except that these components are located below the water storage [6]. The first commercial series of HPWHs produced by Hotpoint Co. came out in the 1950s [14]. They came in two basic models based on the placement of condensers, i.e. immersed in the tank or wrap-around the tank. In general, the design, components, and appearance were similar to current HPWHs. Enviromaster International (EMI) and Arthur D. Little, with support from U.S. Department of Energy program through Oak Ridge National Laboratory (ORNL), developed a new HPWH based on a patented design by Arthur D. Little in 1999 [17, 27]. This HPWH used an identical electrical hookup as existing electric resistance water heaters; thus eliminating additional plumbing or condensate drain requirements. It also used a small and inexpensive refrigeration compressor, wrapped-coil condenser, and adopted the conventional water tank without water pumps. Ease of installation and maintenance are also part of the design consideration, allowing plumbers to apply standard practices for installation. ORNL worked further on improving the system efficiency, which resulted in an energy factor (EF) of 2.47. This design was a prototype for many current HPWHs in the U.S. market.

Current available HPWHs come in limited range of storage tank volumes, usually between 50 and 80 gallons. Most designs have heat pump heating rates of 5,300-9,300 Btu per hour, come with two backup electric resistance elements (1,700-4,000 Watts), and uses R-134a or R-410a refrigerant. HPWHs has not evolved drastically since early 2000s, although manufacturers have added a more user-friendly control system into their products, which gives the users greater flexibility to adjust water temperature and determine the operation mode based on their needs. Some of the most common operation modes available through the control panels are heat pump-only, electric-only, and hybrid modes. The heat pump mode uses only the heat pump system to heat water. This mode is the most energy efficient because back-up elements are not allowed to come on. However, the 
time it takes to heat an entire tank-full of water, or the recovery time, can be long; with a full tank reheat generally taking from 4-6 hours. Under hybrid mode, back-up electric element(s) will supplement the heat pump's output when necessary. As a result, the recovery rate in this mode is quicker; yet, in this mode, the HPWH unit is less efficient than when in heat pump mode. HPWHs operating in electric mode work the same as conventional electric water heater do, using only the resistance element to heat water. Electric mode has the fastest recovery of all three modes but has the lowest overall efficiency. This mode would typically only be used in the event of a refrigerant system or control failure. In addition, the element would come on and work when the ambient air temperature is very low or the tank temperature reaches some limits below the set-point temperature.

Another important component of HPWHs that has gained technological advancements over the years is the compressor. The conventional compressor system when used in heat pump at high water temperature would create high condensing pressure, which would in turn increase energy consumed by the motor and reduce efficiency. Unlike conventional system that only operates at full capacity, dual-stage compressors were developed to allow operation at any capacity levels. Such compressor saves large amounts energy and minimizes wear. Another advanced compressor that substantially improves efficiency of heat pump is the scroll-type system. New type of scroll compressors such as revolving vane compressor, which consists of rotating cylinder that moves with the compressing mechanisms, can achieve efficiency as high as $95 \%$ and reduce energy use by up to $80 \%$ compared to conventional compressors [100]. Scroll compressors are also more reliable than conventional compressors because they have fewer moving parts. Scroll compressors with liquidinjection technique have been studied for use with heat pumps under low temperature applications, making it suitable for a wider range of climate conditions. Driven by the environmental concerns from the use of refrigerants, researchers have started to develop novel compressor systems that are based on electric potential gradient associated with electrochemical processes, with initial results already showing heat pump COP of 3.4 [101]. Although current generation of residential HPWHs in the market has not integrated the latest development in compressor technologies, in the future, HPWHs are expected to include more efficient and reliable compressors.

\section{Operation Efficiency}

HPWH operation efficiency is determined by the amount of water heating generated by the heat pump components and the overall electrical energy consumed. The efficiency indicator is termed Coefficient of Performance (COP). The following equation governs the calculation of COP: 
$\mathrm{COP}=\frac{\text { Delivered Energy }}{\text { Input Energy }}$

In the U.S., the efficiency of HPWHs are reported using the Energy Factor (EF), which is equivalent to COP but determined based on a series of standard test conditions [20]. Effective on July 13, 2015, the EF values are replaced with the new uniform efficiency descriptor, Uniform Energy Factor (UEF), which is determined using a new test method that includes new draw patterns and test conditions. The uniform efficiency descriptor was developed in response to the American Energy Manufacturing Technical Correction Act (AEMTCA), Public Law 112-210, which requires DOE to establish a uniform efficiency descriptor and accompanying test method. The new test method uses the same ambient dry-bulb condition as previous test method, which is $67.5^{\circ} \mathrm{F} \pm 1{ }^{\circ} \mathrm{F}$. The ambient relative humidity is to be maintained at $50 \% \pm 2 \%$, slightly different from previous requirement of a relative humidity between $49 \%$ and $51 \%$. The new test method uses the same supply water temperature as previous test method, i.e. $58^{\circ} \mathrm{F} \pm 2^{\circ} \mathrm{F}$. However, the outlet water temperature is lowered to $125^{\circ} \mathrm{F} \pm 5^{\circ} \mathrm{F}$, from previous tank temperature of $135^{\circ} \mathrm{F} \pm 5^{\circ} \mathrm{F}$. Another big change in this new test procedure is draw pattern, which is defined as the number, flow rate, length, and timing of hot water removal from the water heater during testing The new draw pattern would be assigned based on first-hour rating results, and there are in a total of four draw patterns: very-small-usage, low-usage, medium-usage and high-usage. These four draw patterns vary in total gallon volume, schedule and flow rate. The total volume drawn for each draw pattern is 10 gallon, 38 gallon, 55 gallon and 84 gallon. Details about how draw pattern is assigned and specifics of each draw pattern are explained in Federal Register Vol.79, No. 133 [20]. These new draw patterns which are based on field data on hot water use suggest that the UEF would be more representative of field performance of water heaters that the EF.

Various field deployment studies worldwide have shown that HPWHs offer COPs that are about twice (or more) compared to the conventional electric resistance water heaters. Merrigan and Parker collected HPWHs data from sixteen homes located in Florida over two years [28]. They calculated average COP of 1.5, or about twice the average $\mathrm{COP}$ of other monitored electric resistance water heaters ( $\mathrm{COP}=0.82 ; \mathrm{N}=18$ ). Two recent studies conducted in Northeast regions of the U.S. shows that currently available of HPWHs can be applied in colder climate and, despite the negative impact of low ambient conditions, the HPWHs still maintain higher COPs than conventional electric resistance water heaters and meet the hot water needs [1, 21]. Another recent study conducted in Australia, which combined performance analysis from laboratory measurements with simulations to determine performance of HPWHs under various site-specific characteristics and system features, highlights that $\mathrm{COP}$ and storage capacity are the most critical performance factors, followed by variation on water usage and other site specific conditions [102]. The measured average COPs in the field studies were in the range of 
1.4-3.0. On the other hand, these studies also reveal potential for performance improvements, better system with greater reliability, and increased operational efficiency. Various factors, such as water temperature, ambient air temperature, control design, and system components, influenced HPWHs' performance. In the following discussion, we have categorized the literatures into these key areas where researchers often focus their evaluation leading to introduction of novel techniques, materials, and equipment to improve performance and efficiency aspects of HPWHs.

\subsection{Performance under low or extreme ambient conditions - defrost strategies and combined systems}

Installation locations can affect performance, in particular, the operation efficiency, because of diurnal and seasonal variations in thermal conditions. This is because air source HPWHs use air surrounding the heat pump as heat source. Some mathematical and empirical models of HPWH system have been used demonstrated the strong negative impact of ambient air temperature on HPWH efficiency [29, 30]. This is consistent across all HPWHs regardless of refrigerant types, including CO2. Other studies have shown that overall system COP will increase with ambient temperature [31, 32], by elevating the evaporation temperature and pressure [33, 34].

Evidences of negative impacts of low ambient temperatures on performance and efficiencies have been demonstrated by some studies in the colder climate region. National Renewable Energy Laboratory (NREL) monitored 14 units of three HPWH models in the Northeast region for about one year [1] and Northwest Energy Efficiency Alliance (NEEA) tested 30 units of a HPWH model in the Northwest region in 2013 [21]. Both studies conclude that HPWHs operate at higher efficiencies when they are located in warmer indoor locations. Exposures to lower air temperature (below $60^{\circ} \mathrm{F}$ or as low as $40^{\circ} \mathrm{F}$ ) have been associated with COPs below 2.0. The field studies, however, did not investigate or report the extent of frost issues, nor discuss the defrost mechanisms of the studied units.

Heat pumps that operate under low ambient air temperature (below $40^{\circ} \mathrm{F}$ ) will have frost build-up on the coil surface. Frost accumulation and ice formation increase thermal resistance and pressure drop across the heat exchanger. This process restricts airflow and reduces heat transfer across the evaporator, causing a drop in system heating capacity, potential mechanical problems, and system shutdown [35]. Frost conditions will eventually lead to failure to meet load demand, frequent activation of resistance element, and reduction of overall efficiency.

All HPWHs are equipped with defrosting mechanisms. However, inadequate defrosts under extreme conditions or inefficient design of defrost mechanisms can lead to performance issues. Researchers have investigated frost accumulation process. They also explored different approaches to overcome slow heat recoveries by delaying or 
shortening defrost period and minimizing frost build-up. Frost growth and morphology includes three stages: 1) the initial stage where a thin frost layer of condensed water begins forming on the fins and tubes (COP continues to increase), 2) the second stage where granular ice begins to appear on the thin layer (COP increase reaches pseudo-steady level or slightly reduced); and 3) the final stage where column-shaped ice crystals are forming (COP decreases rapidly) [35]. Jiang et al. [36] provides an example of the impact of frosting stages on COP. During the initial deposition of frost (first 15 minutes), the tested system reached a COP of 2.81. In the second stage of frost growth (15- 83 minutes), COP gradually increased to 2.89 . As the frost formed ice crystals (83-120 minutes), COP dropped quickly to 2.60.

A method to reduce amount of ice built-up is by extracting moisture from the air. A heat exchanger coated by solid desiccant could prevent frosting by means of dehumidifying the air before it enters the evaporator. This system was able to achieve COP values in the range 3.3-3.8 [37]. Both microchannel and finned-tube systems have been proposed as evaporator design for air-source heat pump [38]. Under non-frosting condition, when compared to finned-tube evaporators, the microchannel system could increase heating capacity by $10 \%$. The testing also revealed that microchannel system COP was higher at 2.73 compared to that of finned-tube COP of 2.69. However, testing under frosting conditions showed that microchannel needed much more defrosting period than the finned-tube system and that the proper distribution of refrigerant in the system is required to improve efficiency. A novel defrosting control method based on the degree of refrigerant superheating could impel the defrost process to start 15-20 minutes earlier, which reduced frost built-up and lowered electric element operation [36]. In other words, the control method would allow for extended operation of the system at higher COP. Another method used cross hot-gas bypass defrosting method to shorten defrost time [39]. Air at higher temperature is blown across the coils to melt frost on the airside heat exchanger. A four-way reversing valve was used to reverse the heating operation, which allowed the heat pump to continue operation even during defrost mode. The test unit was able to achieve COP of up to 3.5 and maintained COP above 1.0 while defrost occurred.

Aside from defrosting mechanisms, researchers have attempted to introduce additional systems or components that would allow extended range of operating temperature. Refrigerant injection techniques have shown great potential for improving performance of heap pump water heating under low ambient temperature [97]. The two typical cycles used for refrigerant injection are the internal heat exchanger and flash tank cycles. The techniques can be incorporated as add-on/ combined system to the HPWH. A study has demonstrated that incorporating a ductless heat pump that uses refrigerant injection techniques with inverter-driven compressor allowed HPWHs to continue to operate below freezing temperature [98]. However, the water heating efficiency was not significant improved with the combined systems (COP of 1.8) and further research on modified systems is 
needed.

While these technologies or techniques aim to provide solution to the frosting issue under the low ambient temperature condition, most studies have been limited to improving efficiency of the heat pump system in laboratory settings. These techniques have not been adopted and tested for the currently available HPWHs, where issues pertaining to low ambient temperature application still exists [40]. Furthermore, there is a need to assess economic feasibility of upgrading existing HPWH design with more advanced defrosts mechanism. For example, the cost for adding a four-way reversing valve may make an already high cost of the HPWHs even higher, which could dampen market penetration of the product. On the other hand, the application of solid desiccant coating on the heat exchanger can be an economically feasible option but it's effectiveness over time may decline and thus negate the initial benefit. In addition, these studies should address mild-to-cold climate application because system modification or addition for low-to-extreme cold conditions may not be suitable for higher temperature ranges. Considering economic and technological aspects, future studies should focus on basic system or component changes that could improve and maintain the heat pump performance and efficiency without the need for adding components, such as modifying evaporator design using microchannel and finnedtube systems.

Table 1 Studies showing impacts of ambient temperature on HPWH operation

\begin{tabular}{|l|l|l|}
\hline \multicolumn{1}{|c|}{ Low temperature impacts } & Reference & \multicolumn{1}{c|}{ Year } \\
\hline $\mathrm{T}_{\mathrm{amb}} \downarrow, \mathrm{HPWH}$ efficiency $\downarrow$ & 29,30 & 1994,2010 \\
\hline $\mathrm{T}_{\text {evaporator }} \&$ pressure $\uparrow, \mathrm{HPWH}$ efficiency $\uparrow$ & $\begin{array}{l}31,32,33, \\
34\end{array}$ & $\begin{array}{l}2007,2010, \\
2010,2008\end{array}$ \\
\hline $40 \mathrm{~F} \leq \mathrm{T}_{\mathrm{amb}} \leq 60 \mathrm{~F}: \mathrm{COP}<2.0$ & 1,21 & 2013 \\
\hline Frost build up $\uparrow$ when $\mathrm{T}_{\mathrm{amb}}<40 \mathrm{~F}:$ limit airflow and heating capacity & 35 & 2008 \\
\hline Frost formed ice crystal: COP $\downarrow(10 \%)$ & 36 & 2013 \\
\hline
\end{tabular}

Table 2 Studies demonstrating defrost strategies in HPWH

\begin{tabular}{|l|l|l|l|l|}
\hline \multicolumn{1}{|c|}{ Defrost method } & \multicolumn{1}{|c|}{ Outcomes } & \multicolumn{1}{|c|}{ COP } & Reference & Year \\
\hline $\begin{array}{l}\text { Novel defrost control based on } \\
\text { degree of refrigerant superheating }\end{array}$ & $\begin{array}{l}\text { Impel defrost process to } \\
\text { start 15-20 minutes earlier }\end{array}$ & -- & 36 & 2013 \\
\hline Heat exchanger & Dehumidify air & $3.3-3.8$ & 37 & 2012 \\
\hline Microchannel and finned-tube system & $\begin{array}{l}\text { Proper distribution of } \\
\text { refrigerant needed }\end{array}$ & 2.7 & 38 & 2010 \\
\hline Cross hot-gas bypass & Shorten defrost period & $1.0-3.5$ & 39 & 2013 \\
\hline
\end{tabular}




\subsection{Refrigerants}

For over four decades, R22 had been the refrigerant of choice for heat pump systems, until in the early 2000s when it was phased out because of its detrimental impacts on the ozone layer and global warming [41]. As a result, other blends of hydrofluorocarbons (HFCs), such as R134a and R410a, have been widely adopted as replacements. Most of currently available HPWHs use R134a because it is an established product with wide applications and substantial energy efficiency potential. Koury et al. (2013) simulated dynamic behavior of a prototype using R134a as refrigerant and found that it can reduce compressor work time, which lead to improved efficiency [42].

Operation efficiency of systems using R134a and R410a are commonly compared with R22 applications. The use of R134a is commonly associated with a 25\% increase in COP than R22 [43]. Many studies on R134a have focused on environmental impacts, particularly the global warming potential [43]. Depending on system design, HPWHs with R410a could achieve higher COPs than some systems with R134a [44]; however, side-by-side examination is needed to fully evaluate the differences in performance. A combination of R134a and R410a (refrigerant cascade cycle) could help overcome the rising compression ratio at low ambient temperature, optimize operation with two refrigerant cycles, and maintain an overall COP of 2.0 even during winter seasons $[45,46]$. Both refrigerants are not without limitations. R134a has limited capacity for heating and relatively high cost because of changes in the system to prevent leakage. The cost for recycling R134a is quite high, whereas R410a needs to operate at a high pressure that could cause vibration and noise issues.

It is a global consensus that climate change mitigation should focus on the reduction of greenhouse gas emissions. With increasing demand for refrigerants that lower global warming potential, $\mathrm{CO}_{2}$ has been proposed as an alternative natural refrigerant type for heat pumps, which other than its environmental benefits also maintain a relatively higher operational efficiency than other refrigerants. The investigations on trans-critical $\mathrm{CO}_{2}$ (also known as R744) for heat pumps were initiated by Lorentzen in the early 1990s [47] and studies on the use of $\mathrm{CO}_{2}$ for improving HPWHs efficiency are still ongoing [48, 49]. $\mathrm{CO}_{2}$ could achieve high efficiency because of the temperature glide in $\mathrm{CO}_{2}$ exothermic process that yields high heating capacity. In other words, it could heat up water to a relatively high temperature in a short period of time [50]. HPWHs that use $\mathrm{CO}_{2}$ as refrigerant are often named $\mathrm{CO}_{2}-\mathrm{HPWH}$. $\mathrm{CO}_{2}-\mathrm{HPWH}$ is considered a relatively new technology and researchers are still working to improve system performance. Topics include $\mathrm{CO}_{2}$ pressure modification using $\mathrm{S}$-shaped heat exchanger [51], add-on solar booster which was tested to improve system performance to an average of 2.38 [52], a bigger evaporator along with a narrower design of the gas cooler could boost system COP to up to 8 
[53]. Experimental studies have shown that $\mathrm{CO}_{2}-\mathrm{HPWH}$ could reach an average COP of greater than 4.0 [49]. Compared with other refrigerants, such as $\mathrm{R} 134 \mathrm{a}, \mathrm{CO}_{2}$ refrigerant showed better performance in heat pump systems. Cecchinato et al compared $\mathrm{CO}_{2}$ with $\mathrm{R} 134 \mathrm{a}$ for tap water heat pump systems, they found that with temperature stratification optimization on water tank, COP could reach 4.0-4.9 in Winter, and 7.0-9.0 in Summer [54].

Development of $\mathrm{CO}_{2}-\mathrm{HPWH}$ for use in the U.S is still in its early stage and there are quite a few challenges associated with this technology. The most recognized challenge is a high production cost. A storage type $\mathrm{CO}_{2-}$ HPWH can cost over US $\$ 4,000$ with installation. Other challenges in this technology are: a high design pressure requirement for components, low critical temperature of $\mathrm{CO}_{2}$, and various additional components requirements, e.g. internal heat exchanger, safety equipment [55]. The U.S. Department of Energy is currently working with ORNL on developing a prototype that meets water heating standards, and at the same time can be introduced to the market at a reasonable price by third quarter of 2015 [56]. Future research should continue to assess the performance and feasibility of cascade refrigeration cycle techniques; and conduct laboratory-based testing of new $\mathrm{CO}_{2}-\mathrm{HPWH}$ prototypes, followed by full scale field studies to assess products' reliability and compatibility in the U.S. In the longer term, heat pump water heater research should look beyond current vaporcompression technology and invest in studies to apply promising alternative technologies such as caloric energy conversion for heat pump or refrigeration, which has demonstrated improvements in energy efficiency and reduction in environmental impacts [99].

Table 3 Impacts of refrigerants on HPWH performance and efficiency

\begin{tabular}{|l|l|l|l|l|}
\hline Refrigerants & \multicolumn{1}{|c|}{ Observations } & \multicolumn{1}{|c|}{ COP } & Reference & Year \\
\hline R134a & Compressor runtime $\downarrow$, HPWH efficiency $\uparrow$ & -- & 42 & 2013 \\
\hline R134a, R22 & -- & $20 \%$ increase for R 134a & 43 & 2004 \\
\hline R410, R134a & -- & R 410 R 134a & 44 & 2003 \\
\hline R410, R134a & $\begin{array}{l}\text { R410 \& R134a improved compression ratio at } \\
\text { low ambient temperature condition }\end{array}$ & 2.0 & 45,46 & 2013 \\
\hline R744 & -- & $>4.0$ & 49 & 2012 \\
\hline R744 & $\begin{array}{l}\text { Temperature glide in CO2 exothermic } \\
\text { increased heating capacity }\end{array}$ & -- & 50 & 2098 \\
\hline R744 & With add-on solar booster & 52 & 2013 \\
\hline R744 & With bigger evaporator \& narrower gas cooler & Up to 8.0 & 53 & 2013 \\
\hline R744, R134a & R744 has better performance than R134a & $\begin{array}{l}\text { Winter: 4.0-4.9 } \\
\text { Summer: 7.0-9.0 }\end{array}$ & 54 & 2012 \\
\hline
\end{tabular}




\subsection{Advanced materials and add-on devices}

Phase change material (PCM) is a latent heat storage material, which transfers thermal energy between different states of matter, i.e. solid and liquid [57]. Paraffin is one of the most common materials considered for PCM [58]. Other materials used in heat pumps include, but not limited to, hydrated salts, eutectic salts, and silica gel [59]. PCM has high heat storage density, as well as the ability to maintain relatively constant operation temperature during phase changes [60]. A single unit volume of PCM could store 5-14 times more heat than materials like water [57]. As a result, PCM could be used as thermal storage systems to improve HPWH operation efficiency.

Potential application of PCM in heat pump systems has been recognized since early $21^{\text {st }}$ century [59]. Since then there have been a number of studies demonstrating PCM application in heat pumps, mostly for heating and cooling technologies. For example, Niu et al designed a triple-sleeve energy storage exchanger that consists of three passes of copper tubes. The heat exchange had PCM embedded between the outer tube and inner tube functioning as an energy storage cell. The COP of studied heat pump system in heating mode was able to reach up to 3.9 [60]. The application of PCM in HPWHs only began in the past ten years. In 2008, Long et al. (2008) designed a prototype of HPWH with PCM materials [61]. The PCM component was designed as heat storage during off-peak period and release heat during peak period. This system had an average COP of over 3.08. Taking one step further, Wu et al (2012) incorporated PCM in a cascade HPWH, which used two different refrigerants [58]. The system was designed such that, each refrigerant could operate at its own optimal range of operation conditions [58]. The use of PCM was able to produce an additional $407 \mathrm{~kJ}$ of heating energy for the water tank. Despite the relatively small number, this had helped the system to achieve a COP of up to 3.2 in cascade mode. The researcher underlined that PCMs with larger capacity and higher heat transfer rate could make HPWHs even more efficient.

New components, such as condenser and ejector, could also increase system efficiency by improving heat transfer and compressor operation efficiency. Studies have showed that decreasing diameter of the heat exchanger tubes has positive impact on heat transfer coefficient [62]. This smaller tube, often called the minichannel heat exchanger has already been widely used in vehicles air conditioning [63]. If this concept being applied to HPWHs, the use of mini-tube condenser geometries could reduce refrigerant quantity significantly. Comparing HPWHs with mini-tube heat exchanger and the conventional macro-tube type, results clearly showed higher COP values for HPWH with the mini-tube. The difference in COP could be as high as 0.5 [63]. An ejector could be added to the refrigeration system as an expansion device. An ejector could produce a higher 
level compressor suction pressure than that in the evaporator, therefore reducing the power input of a compressor. This could improve the performance of compression systems substantially [64]. Adding an ejector associated with a subcooler to a novel vapor compression heat pump cycle could be improved COP by up to $6.9 \%$ $[65]$.

Waste heat of HPWHs can be recovered by adding a heat recovery-preheater. Chen et al. (2012) developed and tested a prototype with heat recovery-preheater [66]. This unit could recover waste heat by preheating the inlet cold water before the heat pump system heats it. The waste heat would then be released in heat recoverypreheater and heat pump system. This cascade utilization of waste heat enable the unit to be able to achieve a COP in the range of 4.0-5.5 even in winter or about twice as much as conventional HPWHs.

The application of PCM in HPWHs showed promising results in various experimental studies. However, a successful implementation of this material with currently available HPWHs has not been demonstrated. Furthermore, evaluation should be conducted in the field where variations of thermal conditions could potentially reduce the effectiveness of the PCM. An optimization study to determine the right blend of PCM materials for HPWHs and a reliability assessment study would be useful for the manufacturers. A number of new or optimized components have been proven to improve system efficiency; however, its compatibility with current HPWHs and their potential adoption in the market need to be studied further.

Table 4 Applications of new materials and components on HPWH efficiency

\begin{tabular}{|l|l|l|l|l|}
\hline \multicolumn{1}{|c|}{ Materials/ components } & \multicolumn{1}{c|}{ Application } & \multicolumn{1}{c|}{ COP } & \multicolumn{1}{c|}{ Reference } & \multicolumn{1}{c|}{ Year } \\
\hline PCM & Triple-sleeve energy storage & Up to 3.9 & 60 & 2013 \\
\hline PCM & Heat storage & $>3.08$ & 61 & 2008 \\
\hline PCM & Cascade system & Up to 3.2 & 58 & 2012 \\
\hline Condenser & Mini-tube condenser & $\begin{array}{l}0.5 \text { increase than } \\
\text { macro-tube type }\end{array}$ & 63 & 2013 \\
\hline Ejector & Add-on to sub-cooler & $6.9 \%$ increase & 65 & 2011 \\
\hline Heat recovery (pre-heater) & Cascade utilization of waste heat & $4.0-5.5$ & 66 & 2012 \\
\hline
\end{tabular}

\subsection{Schedule optimization}

Another strategy to increase operation efficiency is schedule optimization. An intuitive control strategy that could interactively determine how and when the heat pump and/or electric element should operate in meeting 
the demand could strongly affect the performance and overall efficiency of the HPWHs. Not only that this approach would minimize heat losses substantially but also it could help reduce utility power load during peak hours. Unfortunately, research on this aspect has not received a lot of attention. A concept validation using a simulation model shows that optimized schedule of operation could elevate COP to 5.5 at an ambient temperature of $35^{\circ} \mathrm{C}$ [63]. Because low ambient air temperature has negative impact on HPWHs operation efficiency, the optimal operation time of HPWHs should be adjusted to hours when the ambient air temperature is the highest. Guo et al. (2011) identified the optimal start-up time of HPWHs to be 12:00-14:00 and show that by adopting an optimized schedule, the system could maintain COP of 2.8 - 5.5 [67].

\subsection{Multi-functional application}

HPWH operation produces a free byproduct, which is cooled air exiting the heat pump system. Researchers and manufacturers have recognized this as potential source for space cooling; or in some cases, an additional space heating burden. A simulation study of HPWHs operation in three U.S. regions have indicated a substantial space heating penalty of HPWH operation [68]. In another study, researchers attempted to measure space cooling benefits of HPWH operation in 5 households in the U.S., however their experiments to understand the heating and cooling interaction were inconclusive and only one site with conditioned basement installation had data that could be used to calculate an interaction factor. This factor was determined to be 0.65 , which means that every unit of heat energy extracted from the air was replaced by $65 \%$ of energy from space heating system [2].

With the premise that HPWHs could be used for space cooling, multi-function heat pump system (MFHPS) was developed combining heat pump system for water heating and air conditioning for space cooling. Laboratory studies on MFHPS during the period of 1987-2013 have shown about 16\%-20\% improvement in COP. A prototype MFHPS was evaluated in restaurants and the system achieved COPs of 2.0-3.0 or about 20\% higher than that of water heating only application [69]. Another MFHPS prototype achieved an even higher average COP values of 4.0 with combined water heating and space cooling application [70]. Cakir et al. (2013) tested a MFHPS system with a scroll compressor and the system was able to achieve a COP of 3.9 [71]. The substantial increase in efficiency could be attributed to a higher exergy of an MFHPS when used for space cooling and water heating (13\% more output could be obtained from the system) compared to for water heating only $(10.5 \%)$ [72]. 
Table 5 Multi-functional HPWH applications and efficiency

\begin{tabular}{|l|l|l|l|}
\hline \multicolumn{1}{|c|}{ Applications } & \multicolumn{1}{c|}{ COP } & Reference & \multicolumn{1}{c|}{ Year } \\
\hline Water heating + space cooling & $2.0-3.0$ & 69 & 1987 \\
\hline Water heating + space cooling & 4 & 70 & 2003 \\
\hline MFHPS with scroll compressor & 3.9 & 71 & 2013 \\
\hline Water heating + space cooling & $\begin{array}{l}\text { Higher energy } \\
\text { output }\end{array}$ & 72 & 2013 \\
\hline
\end{tabular}

\section{Energy use and energy savings of HPWH and demand-side management approach}

Air-source HPWHs can provide significant energy savings in various climate zones, even when applied in colder regions such as the Pacific Northwest. For instance, compared to a typical electric resistance water heating systems, a HPWH could achieve up to $63.7 \%$ savings in annual energy use when installed in warmer Houston, TX, or up to $40.2 \%$ when installed in a cooler Chicago, IL [40]. A study by a utility company showed that HPWHs could save energy most in the inland areas and have the least impact in coastal areas where the weather is relatively cooler [73].

Adding a recirculation loop to HPWHs could lead to significant energy savings. A well-insulated recirculation loop system could reduce fuel cost by up to 50\% [74]. Other new components and materials also provide energy saving benefits. Mini-tube condenser geometries could reduce refrigerant quantity significantly, which is equivalent to $69 \%-82 \%$ in energy savings [63]. PCM can reduce the off-peak electricity tariff as an energy storage system. However, the impact on energy saving have not been evaluated [75].

HPWHs returned the market twice in the 1970s and 2000s because of the increasing electricity prices [26]. This is because HPWHs could save significant amount of energy compared with ESWHs. A 50 gallon HPWH consumed about $70 \%$ less energy than a standard 50 gallon ESWH [76]. This means a HPWH can provide much more heat with the same amount of energy input as an ESWH. As early as 1985, a HPWH tested in New Zealand was able to realize 50\% -85\% of annual energy saving, if compared with an ESWH [77]. Two households were simulated to be able to achieve $422-1682 \mathrm{kWh} / \mathrm{yr}$ saving in energy if switch from ESWHs to HPWHs, the associated carbon emission reduction was 0.549-2.187 ton/year [78]. Comparing s 50-gal HPWH with a typical 50-gal ESWH with an EF of 0.92, the modeled annual energy savings for 1,2, and 3+ household size are 1,750 to $2,200 \mathrm{kWh} / \mathrm{yr}$, with more savings yield as the increase of household size [79]. 
This is further validated in a number of field studies. AIL Research tested15 Nyletherm-1 units in CT and found that these HPWHs reduced energy use by 40\%-50\%, or 971-4,488 kWh/yr, compared with conventional ESWH [80]. In another study carried out on Northeast region in the US, 14 HPWHs saved more than 50\% in energy compared with a standard ESWH [1]. HPWHs tested in Northwest region in the US achieved an average of $43 \%$ saving in electricity use, compared with a standard 50-gal ESWH [21]. Computer simulation and modeling further validated this. PG\&E modeled HPWHs energy impact using eQuest modeling and Excel spreadsheet. Based on Database for Energy Efficiency Resources (DEER) 2008, Rheem HP50 HPWH could save 3432.8 4504.1 kWh/yr over ESWHs [73]. If 4,700 ESWHs were replaced with HPWHs, Northeast Utilities' (NU) HotShot program estimated the lifetime saving to be more than 200,000 MWh [81]. If convert all ESWHs to HPWHs in the US, the estimated energy saving is 490 average megawatts (aMW) by 2030 for Northwest region alone [21]. The saving is a lot more on nationwide, which is estimated to be 0.7 quads/yr, with associated cost saving of $\$ 7.8$ billion/yr [1].

HPWH's energy saving feature also applies to $\mathrm{CO}_{2}-\mathrm{HPWH}$. Compared with gas fired systems, $\mathrm{CO}_{2}-\mathrm{HPWH}$ could reduce energy use by $75 \%$ while maintaining supply water temperature at $60{ }^{\circ} \mathrm{C}$ [49]. In Japan, where this type of HPWH is the most popular, the estimated potential energy saving was 3.2-10.6 GJ/yr per household if all households in Japan adopt $\mathrm{CO}_{2}-\mathrm{HPWH}$ [82]. As the typical refrigerant for HPWHs, R 134a could not reach the high water temperature required in sanitary application, a commercial application of $\mathrm{CO}_{2}-\mathrm{HPWH}$ could save as high as $20 \%$ in electricity [53].

Energy savings feature of HPWHs makes it more economic feasible on market. According to NREL, the simulated annual operation cost is about \$150/yr for HPWHs, which is significantly lower than ESWH, oil and propane, and comparable to gas water heaters. This comparison result is consistent if expanded to a total life cycle basis. HPWHs had an annualized energy related cost (AERC) ${ }^{3}$ of less than \$400/yr [1]. Although HPWHs cost relatively more upfront (purchase and installation), a 50-gal HPWH with an EF of 2.35 has calculated simple payback period (PBP) of $4.7 \mathrm{yrs}$, and ratio of investment $\left(\mathrm{ROI}^{4}\right)$ of $113 \%$. Using simulated hot water draw pattern, estimated PBP for 1,2 and 3+ household sizes are 6.6yr, 5.8yr and 5.3yr, with longer PBP for smaller households [79].

The energy storage capacity of electric water heaters with tank has been used in demand-side management (DSM) to reduce demand during peak hours [83]. This could potentially avoid costs of installing new power plants for the utilities [84]. DSM is defined as "the planning, implementation and monitoring of those utility

\footnotetext{
${ }^{3}$ AERC represents the equivalent annual cost of the complex cash flow and represents an equivalent annual cost of operating the water heater in present dollars.

${ }^{4} \mathrm{ROI}$ is the ratio of net proceeds to the investment costs, calculated as (total utility savings-measure cost)/measure cost*100\%
} 
activities designed to influence customer use of electricity in ways that will produce desired changes in the utility's load shape, i.e., changes in the pattern and magnitude of a utility's load" by Electric Power Research Institute [85]. HPWHs have lower power consumption than conventional electric water heaters. This makes HPWHs more valuable asset for DSM program. By reducing power demand, HPWHs can help reduce energy use in the overall electricity system [86]. WATSIM simulated HPWHs' load reduction capacity to be $890 \mathrm{~W}$ in the morning and $840 \mathrm{~W}$ in the evening, based on 9-month monitoring data from 15 units in the US [80]. This concept was explored in the field in several countries, and all studies consistently show that HPWHs can be beneficial in shifting peak load and reducing energy use. In South Africa, a HPWH could realize a total peak demand reduction of $36 \%$ in a 200 -occupant hotel. With load reduction and high efficiency, the calculated payback period was 12.5 months (IRR ${ }^{5}: 98 \%$ ). If applied on its full scale to commercial buildings, it could reduce the cost of kilowatt-hour consumption from $35.4 \mathrm{c} / \mathrm{kWh}$ (ZAR) to $7.4 \mathrm{c} / \mathrm{kWh}$ (ZAR) [87]. Ericson carried out a similar project in Norway and the results showed an average consumption reduction of $0.5 \mathrm{kWh}$ per hour for each household [88].

Table 6 Energy savings from HPWHs and improved systems

\begin{tabular}{|l|l|l|l|}
\hline \multicolumn{1}{|c|}{ Application/ comparison } & \multicolumn{1}{c|}{ Energy savings } & Reference & Year \\
\hline HPWH vs. ESWH & 0.7 quads per year & 1 & 2013 \\
\hline HPWH vs. ESWH & 490 aMw by 2030 & 21 & 2013 \\
\hline Houston TX, Chicago IL & $67.3 \%(T X), 40.2 \%(\mathrm{IL})$ & 40 & 2012 \\
\hline $\mathrm{CO}_{2}$-HPWH vs. gas-fired systems & $75 \%$ & 49 & 1998 \\
\hline $\mathrm{CO}_{2}$-HPWH vs. conventional HPWH & $20 \%$ & 53 & 2012 \\
\hline Mini-tube condenser geometries & $69 \%-82 \%$ & 63 & 2013 \\
\hline HPWH vs. ESWH & $3432.8-4504.1 \mathrm{kWh}$ per year & 73 & 2009 \\
\hline well-insulated recirculation loop system & up to $50 \%$ & 74 & 1981 \\
\hline HPWH vs. ESWH & $70 \%$ & 76 & 2013 \\
\hline HPWH vs. ESWH (New Zealand) & $50 \%-85 \%$ & 77 & 1985 \\
\hline HPWH vs. ESWH & $422-1682 \mathrm{kWh}$ per year & 78 & 2011 \\
\hline HPWH vs. ESWH (high efficiency) & $1,750-2,200 \mathrm{kWh}$ per year & 79 & 2012 \\
\hline HPWH vs. ESWH & $971-4,488 \mathrm{kWh}$ per year & 90 & 1982 \\
\hline CO ${ }_{2}$-HPWH (Japan) & $3.2-10.6 \mathrm{GJ}$ per year & 82 & 2009 \\
\hline
\end{tabular}

\footnotetext{
${ }^{5}$ IRR: internal rate of return, often used in net present value calculation. $<$ http://www.investopedia.com/terms/i/irr.asp >
} 
Most studies on DSM focused on peak shift, load reduction and energy saving in the overall electricity system, however there is lack of studies on operation efficiency of HPWHs in DSM programs. If HPWHs in a DSM program are to be controlled and scheduled in an optimal way, the higher operation efficiency may yield more savings in energy use for each household. For example, HPWHs would have different efficiency levels when operated at different time of day, because of temperature variation in water and ambient air. Adding a control with timer to HPWHs which could enable smart operation and schedule based on end user needs and satisfaction could further improve DSM programs.

HPWHs with multi-function application can save substantial amount of energy, particularly when they are being applied for air conditioning. For example, in a field study of 100 HPWHs with multi-function application - mostly in commercial settings - the studied HPWHs had space conditioning benefits of 0.67 Btu at no additional cost [89].

Table 7 Impact of DSM on reduction of power load

\begin{tabular}{|l|l|l|l|}
\hline \multicolumn{1}{|c|}{ Study method } & \multicolumn{1}{c|}{ Load Reduction } & Reference & Year \\
\hline Simulated DSM using WATSIM program & $\begin{array}{l}\text { Day time: } 890 \mathrm{~W} \\
\text { Evening time: } 840 \mathrm{~W}\end{array}$ & 80 & 2002 \\
\hline DSM implemented in a hotel & $36 \%$ & 87 & 2004 \\
\hline DSM implemented in residences & $0.5 \mathrm{kWh} /$ hour per household & 88 & 2009 \\
\hline
\end{tabular}

\section{System operation and reliability}

One of the main problems of HPWH during its early years was operation instability and system reliability issue. One example is inconsistent operation across multiple units of the same model. In 1982, Bernardi et al from ORNL tested 20 HPWH units over 25 months. Certain degree of wear in compressors was observed, and one unit showed signs of premature failure. They concluded that the reliability of the system can be mostly jeopardized by the water tank, and improving anodic protection could help prolong system lifetime [90]. Another set of 20 HPWHs, called WatterSaver units, also experienced control issues and failures [91].

Another example system reliability issue is inconsistent operation across various geographical locations. Over 100 HPWHs tested in hot and humid climate, the study reported largest operational problem caused by poor basic plumbing installations [89]. Details about encountered issues were not discussed in that report. An additional aspect is inconsistent hot water delivery temperature; either not being able to provide hot water at or above a certain temperature, or the delivered hot water being over heated to a very high temperature range. In either case, the HPWH operation is not stable and reliable to be able to heat up water to a desired temperature 
range. Three out of 6 monitored sites in a New Zealand study had a wide temperature range in hot water supply [77], while a field testing of 20 WatterSaver HPWHs in the Northeastern United States showed that the water temperature near the top of the tanks often exceed $150^{\circ} \mathrm{F}$. The latter was caused by the high-temperature safety set point set at $170^{\circ} \mathrm{F}$ and excessive tank stratification [1]. However, there were also some positive results of HPWH operation in the field. The HPWH tested in New Zealand had fast temperature recovery and was able to maintain a high standard of hot water service to all participants. Three out of 6 sites experienced fewer hot water runout events than with conventional electric water heaters of 1.5-2.0 kW capacity, and relatively stable supply hot water temperature [77].

Issues identified in the field inspired development of new generations of HPWHs that are proved to have more stable operation and better reliability. To better address operational issues and market needs identified aforementioned, changes were made in design, including reduced size requirements of heat exchangers and compressors, and reduced the space needed for the heat pump. As a result, these new generations of HPWHs could possibly use smaller evaporator fans and produce quieter systems overall, with a longer lifetime [81].

Ten HPWH units were run through a durability test. The test program was designed to simulate 10 years of normal compressor cycling, or 7300 cycles. Test results showed no compressor, evaporator fan, or power reply failures. Minor issues occurred, such as refrigerant leakage and expansion valve replacement, but were not considered as reliability concern. As of earlier generations of HPWHs, 16 out of 40 units failed because of spliced joints in the sensor lead wires. In conclusion, the new generations of HPWHs had less failure than old generations, in terms of thermostat, control board, compressor operation and delivered hot water temperature [27]. 14 HPWHs monitored in Northeastern US operated well without experiencing the same reliability issues of earlier models, also there was no sign of excessive or inadequate hot water temperature. Only one unit failed in this study but was quickly repaired and then functioned well as others [79]. Nevertheless, various operation issues were discovered in field studies. Of the 15 Nyletherm- 1 units tested by AIL, 2 units developed short cycling, and the cause was not explained in this report [80].

Yet there is still potential to improve system reliability. One approach is to modify existing components. With decreasing temperature of the heat source, reduction in heating capacity and rise in pressure ratio prevent effective utilization of a HPWH. Applying vapor-injection technique in compressor system be a possible solution [92]; regulating electronic expansion valve (EEV) with a novel dual-fuzzy-controller could help select the optimal initial opening and target superheat on the basis of ambient and water temperature [93]; optimizing reservoir size could minimize heat loss and performance degradation [94]; optimal design on capillary tube 
length, filling quantity of refrigerant, the condenser coil tube length and system matching also matters to system reliability [95]

Choosing a different type of refrigerant also help improve system reliability. For example, replacing R134a with R410 (commonly used for air conditioning) was more effective at providing higher outlet water temperature [96]; $\mathrm{CO}_{2}-\mathrm{HPWH}$ is known to have more operation flexibility and being able to produce higher outlet water temperature $[44,52]$. Michael et al compared $\mathrm{CO}_{2}$ with $\mathrm{R} 134 \mathrm{a}$ for commercial HPWH application and found it more reliable under low water temperature condition w ith optimized high side pressure [53].

\section{Conclusion}

Heat pump water heaters (HPWHs) can increase energy savings significantly as demonstrated by a number of studies discussed in this review. The market growth of HPWHs however had been hampered by high costs and a range of technical and operational issues. This slow growth has delayed advancement and integration technologies for HPWH and its potential remained untapped. It is not until recent regulatory changes that HPWHs are propelled to the forefront of energy efficient water heating products and a new generation of HPWHs reemerges in the market. With the regulatory push and market growth, it is has become time critical for HPWH systems to consider advance technologies or strategies that address challenges associated with cost, performance, and efficiency of HPWHs in the field. This review has identified a range of potential technological updates that could augment the current HPWH systems by: incorporating defrost strategies to boost performance under low or extreme ambient conditions; considering suitable refrigerants, their application in HPWHs, and alternatives to vapor-compression technology; applying advanced materials and components to increase capacity of energy (heat) storage and improve operation efficiency; introducing smart control strategies which optimize energy use based on water use schedule; and developing products with multi-function applications. Optimization and technology integration of HPWHs could increase the coefficient of performance from a typical range of 1.8-2.5 to higher range of 2.8-5.5 based on current state of research. Investing in and advancing HPWH technological updates would contribute to an even greater national energy savings. 


\section{Acknowledgment}

The work described in this report was funded by the U.S. Department of Energy's Office of Energy Efficiency and Renewable Energy, Building Technologies Program.

\section{References}

[1] C. Shapiro, S. Puttagunta, Field Performance of Heat Pump Water Heaters in the Northeast, in, NREL, Golden, CO, 2013.

[2] NEEA, Heat Pump Water Heater Model Validation Study, in, Northwest Energy Efficiency Alliance, 2015, pp. 74-75.

[3] E.P. Johnson, Air-source heat pump carbon footprints: HFC impacts and comparison to other heat sources, Energy Policy, 39 (3) (2011) 1369-1381.

[4] I. Blom, L.C.M. Itard, A. Meijer, LCA-based environmental assessment of the use and maintenance of heating and ventilation systems in Dutch dwellings, Building and Environment 11 (45) (2010) 2362-2372. [5] T.G.N. Haldane, The heat pump-an economical method of producing low grade heat from electricity, IEEE, (1930) 666-675.

[6] G. Wilkes, F.M. Reed, U.S. Patent No. 2095017, in, 1937.

[7] F.L. La Porte, U.S. Patent No. 2526032, in, 1950.

[8] G. Electric, U.S. Patent No. 3017162A, in, 1962.

[9] A.D. Little, U.S. Patent No. 4474018A, in, 1982.

[10] J.A. Pietsch, The unitary heat pump industry, ASHRAE, 19 (7) (1977) 15-18.

[11] R.L.Dunning, F.R.Amthor, E.J.Doyle, Research and development of a heat-pump water heater, in, Oak Ridge National Laboratory, 1978.

[12] B.D. Sloane, R.C. Krise, D.D. Kent, Demonstration of a Heat Pump Water Heater, in, Oak Ridge National Laboratory, 1979.

[13] W.P.Levins, A Comparison of Laboratory and Field-Test Measurements of Heat-Pump Water Heaters, in: ACEEE 1982 Summer Study, Santa Cruz, CA, 1982.

[14] J.M.Calm, Heat Pump Water Heaters, Electric Power Research Institute, 1984.

[15] J.E. Dobyns, M.H. Blatt, Heat Pump Water Heater, Electric Power Research Institute, 1984.

[16] S. Bodzin, Air-to-Water Heat Pumps for the Home, Home Energy Magazine Online July/August 1997 (1997).

[17] V.D. Baxter, R.L. Linkous, Heat Pump Water Heater Durability Testing - Phase II in, OAK RIDGE NATIONAL LABORATORY, 2004. 
[18] B.G. Ashdown, D.J. Bjornstad, G. Boudreau, M.V. Lapsa, S. Schexnayder, B. Shumpert, F. Southworth, Heat Pump Water Heater Technology: Experiences of Residential Consumers and Utilities, in, ORNL, 2004. [19] R.A. Zogg, W.J. Murphy, Design Refinement and Demonstration of a Market-Optimized Residential Heat-Pump Water Heater, in, California Energy Commission 2004.

[20] Department of Energy, Test Procedures for Residential and Commercial Water Heaters, Federal Register Vol.79, No. 133, 2014.

[21] F.M. Strategies, NEEA Heat pump Water Heater Field Study Report, Northwest Energy Efficiency Alliance, 2013.

[22] M.A. Brown, E. Gumerman, X. Sun, K. Sercy, G. Kim, Myths and facts about electricity in the U.S. South, Energy Policy, 40 (2012) 231-241.

[23] Department of Energy, Energy Conservation Standards for Residential Water Heaters, Direct Heating Equipment, and Pool Heaters, Federal Register Vol.75, No. 73, 2010.

[24] O. Ibrahim, F. Fardoun, R. Younes, H. Louahlia-Gualous, Review of water-heating systems: General selection approach based on energy and environmental aspects, Building and Environment 72 (2014) 259-286. [25] H. Singh, A. Muetze, P.C. Eames, Factors influencing the uptake of heat pump technology by the UK domestic sector, Renewable Energy, 35 (4) (2010) 873-878.

[26] A. Hepbasli, Y. Kalinci, A review of heat pump water heating systems, Renewable and Sustainable Energy Reviews, 13 (6-7) (2009) 1211-1229.

[27] V.D. Baxter, R.L. Linkous, DURABILITY TESTING RESULTS:Oak Ridge National Laboratory Report "Durability Testing of a

Drop-In Heat Pump Water Heater” in, OAK RIDGE NATIONAL LABORATORY, 2002.

[28] T. Merrigan, D. Parker, Electrical Use, Efficiency, and Peak Demand of Electric Resistance, Heat Pump, Desuperheater, and Solar Hot Water Systems, in: American Council for an Energy Efficient Economy, Asilomar Conference Center, Pacific Grove, CA, 1990.

[29] G.L. Morrison, Simulation of packaged solar heat-pump water heaters, Solar Energy, 53 (3) (1994) 249257.

[30] L.A. Steijger, R.A. Buswell, V. Smedley, S.K. Firth, P. Rowley, An air source heat pump model for operation in cold humid environments, in, 2010.

[31] R.S. Yokoyama, Takeshi; Ito, Koichi; Takemura, Kazuhisa, Influence of ambient temperatures on performance of a CO2 heat pump water heating system, Energy, 32 (4) (2007) 388-398.

[32] Y.B. Tao, Y.L. He, W.Q. Tao, Z.G. Wu, Experimental study on the performance of CO2 residential airconditioning system with an internal heat exchanger, Energy Conversion and Management, 51 (1) (2010) 64-70. 
[33] N. Fernandez, Y. Hwang, R. Radermacher, Comparison of CO2 heat pump water heater performance with baseline cycle and two high COP cycles, International Journal of Refrigeration, 33 (3) (2010) 635-644.

[34] N.E.P. Fernandez, Performance and oil retention characteristics of a CO2 heat pump water heater, Mechanical Engineering University of Maryland, College Park, 2008.

[35] X.-M. Guo, Y.-G. Chen, W.-H. Wang, C.-Z. Chen, Experimental study on frost growth and dynamic performance of air source heat pump system, Applied Thermal Engineering, 28 (17-18) (2008) 2267-2278. [36] Y. Jiang, J. Dong, M. Qu, S. Deng, Y. Yao, A novel defrosting control method based on the degree of refrigerant superheat for air source heat pumps, International Journal of Refrigeration, 36 (8) (2013) 2278 -2288. [37] L. Zhang, T. Fujinawa, M. Saikawa, A new method for preventing air-source heat pump water heaters from frosting, International Journal of Refrigeration, 35 (5) (2012) 1327-1334.

[38] L.-L. Shao, L. Yang, C.-L. Zhang, Comparison of heat pump performance using fin-and-tube and microchannel heat exchangers under frost conditions, Applied Energy, 87 (4) (2010) 1187-1197.

[39] Z. Wang; H. Yang;, S. Chen, Study on the operating performance of cross hot-gas bypass defrosting system for air-to-water screw heat pumps, Applied Thermal Engineering, 59 (1-2) (2013) 398-404.

[40] K. Hudon, B. Sparn, D. Christensen, J. Maguire, Heat Pump Water Heater Technology Assessment Based on Laboratory Research and Energy Simulation Models, in: ASHRAE Winter Conference, National Renewable Energy Laboratory Chicago, Illinois, 2012, pp. 36.

[41] U. EPA, What You Should Know about Refrigerants When Purchasing or Repairing a Residential A/C System or Heat Pump, in.

[42] R.N.N. Koury, R.N. Faria, R.O. Nunes, K.A.R. Ismail, L. Machado, Dynamic model and experimental study of an air water heat pump for residential use, International Journal of Refrigeration, 36 (3) (2013) 674-688. [43] S. Karagoz, M. Yilmaz, O. Comakli, O. Ozyurt, R134a and various mixtures of R22/R134a as an alternative to R22 in vapour compression heat pumps, Energy Conversion and Management, 45 (2) (2004) 181 196.

[44] M.R. Richter, S.M. Song, J.M. Yin, M.H. Kim, C.W. Bullard, P.S. Hrnjak, Experimental results of transcritical CO2 heat pump for residential application, Energy, 28 (10) (2003) 1005-1019.

[45] H. Park, D.H. Kim, M.S. Kim, Performance investigation of a cascade heat pump water heating system with a quasi-steady state analysis, Energy, 63 (2013) 283-294.

[46] N. Park, H. Park, S. Jung, J. Shin, B. Chung, H. Jung, Seasonal performance of thermal storage integrated air source heat pump water heater based on field measurement at reference sites in Korea, in: SAREK 2012 summer annual conference, Korea, 2012.

[47] G. Lorentzen, Trans-critical vapour compression cycle device, in: I.P. Publication (Ed.) WO 90/07683, 1990. 
[48] S. Wang, Y. He, H. Tuo, F. Cao, Z. Xing, Effect of heat transfer area and refrigerant mass flux in a gas cooler on heating performance of air-source transcritical $\mathrm{CO} 2$ heat pump water heater system, Energy and Buildings, 67 (2013) 1-10.

[49] P. Nekså, H. Rekstad, G.R. Zakeri, P.A. Schiefloe, CO2 -heat pump water heater: characteristics, system design and experimental results, International Journal of Refrigeration, 21 (3) (1998) 172-179.

[50] Y. Ma, Z. Liu, H. Tian, A review of transcritical carbon dioxide heat pump and refrigeration cycles, Energy, 55 (2013) 156-172.

[51] T.L.K. Ngo, Yasuyoshi; Nikitin, Konstantin; Tsuzuki, Nobuyoshi, New printed circuit heat exchanger with S-shaped fins for hot water supplier, Experimental Thermal and Fluid Science, 30 (8) (2006) 811-819.

[52] S. Deng, Y.J. Dai, R.Z. Wang, Performance optimization and analysis of solar combi-system with carbon dioxide heat pump, Solar Energy, 98 (Part C) (2013) 212-225.

[53] P. Michael, D.B. Chad, E.P. Stefan, Hrnjak, Development of High Efficiency Carbon Dioxide Commercial Heat Pump Water Heater, in: International Refrigeration and Air Conditioning Conference, 2012.

[54] L. Cecchinato, M. Corradi, E. Fornasieri, L. Zamboni, Carbon dioxide as refrigerant for tap water heat pumps: A comparison with the traditional solution, International Journal of Refrigeration, 28 (8) (2005) 12501258.

[55] J. Pettersen, Pros and Cons of the Options, in, Norwegian University of Science and Technology, 2003. [56] DOE, CO2 HEAT PUMP WATER HEATER, in, 2009.

[57] A. Sharma, V.V. Tyagi, C.R. Chen, D. Buddhi, Review on thermal energy storage with phase change materials and applications, Renewable and Sustainable Energy Reviews, 13 (2) (2009) 318-345.

[58] J. Wu, Z.W. Yang, Qinghao, Y. Zhu, Transient behavior and dynamic performance of cascade heat pump water heater with thermal storage system, Applied Energy, 91 (1) (2012) 187-196.

[59] G. Suppes, Heat pump using phase change materials, in: U. Patent (Ed.) US20030131623 A1, 2003.

[60] F. Niu, L. Ni, Y. Yao, Y. Yu, H. Li, Performance and thermal charging/discharging features of a phase change material assisted heat pump system in heating mode, Applied Thermal Engineering, 58 (1-2) (2013) 536-541.

[61] J.-Y. Long, D.-S. Zhu, Numerical and experimental study on heat pump water heater with PCM for thermal storage, Energy and Buildings, 40 (4) (2008) 666-672.

[62] Y.-Y. Yan, T.-F. Lin, Condensation heat transfer and pressure drop of refrigerant R-134a in a small pipe, International Journal of Heat and Mass Transfer, 42 (4) (1999) 697-708.

[63] O. Ibrahim, F. Fardoun, R. Younes, H. Louahlia-Gualous, Air source heat pump water heater: Dynamic modeling, optimal energy management and mini-tubes condensers, Energy, 64 (2013) 1102-1116. 
[64] P. Chaiwongsa, S. Wongwises, Experimental study on R-134a refrigeration system using a two-phase ejector as an expansion device, Applied Thermal Engineering, 28 (5-6) (2008) 467-477.

[65] X. Chen;, Y. Zhou, J. Yu, A theoretical study of an innovative ejector enhanced vapor compression heat pump cycle for water heating application, Energy and Buildings, 43 (12) (2011) 3331-3336.

[66] Z. Chen, W. Tao, Y. Zhu, P. Hu, Performance analysis of air-water dual source heat pump water heater with heat recovery, Science China Technological Sciences, 55 (8) (2012) 2148-2156.

[67] J.J. Guo, J.Y. Wu, R.Z. Wang, S. Li, Experimental research and operation optimization of an air-source heat pump water heater, Applied Energy, 88 (11) (2011) 4128-4138.

[68] L. Morrison, J. Swisher, Analysis of the performance and space-conditioning impacts of dedicated heatpump water heaters, in, 1980.

[69] B.A. Pritchard, Computer modeling of heat pump water heaters in restaurant applications, UNIVERSITY OF WISCONSIN-MADISON, 1987.

[70] J. Ji, T.-t. Chow, G. Pei, J. Dong, W. He, Domestic air-conditioner and integrated water heater for subtropical climate, Applied Thermal Engineering, 23 (5) (2003) 581-592.

[71] U. Çakir, K. Çomakl, Ö. Çomakl, S. Karsl, An experimental exergetic comparison of four different heat pump systems working at same conditions: As air to air, air to water, water to water and water to air, Energy, 58 (2013) 210-219.

[72] X. Sun, J. Wu, R. Wang, Exergy analysis and comparison of multi-functional heat pump and conventional heat pump systems, Energy Conversion and Management, 73 (2013) 51-56.

[73] H.M. Group, Energy Performance Analysis for Heat Pump Water Heaters - ETCC \# 0916, in, Pacific Gas and Electric Company, 2009.

[74] L. Morrison, Performance analysis of dedicated heat-pump water heaters in an office building, in, 1981.

[75] F. Agyenim, N. Hewitt, The development of a finned phase change material (PCM) storage system to take advantage of off-peak electricity tariff for improvement in cost of heat pump operation, Energy and Buildings, 42 (9) (2010) 1552-1560.

[76] C. Colon, D. Parker, Side-by-Side Testing of Water Heating Systems: Results from the 2010 - 2011

Evaluation, in, Florida Solar Energy Center/University of Central Florida, Cocoa, Florida, 2013.

[77] J.A. Anderson, R.A. Bradford, C.G. Carrington, Assessment of a heat pump water heater, International Journal of Energy Research, 9 (1) (1985) 77-89.

[78] J.J. Guo, J.Y. Wu, R.Z. Wang, A new approach to energy consumption prediction of domestic heat pump water heater based on grey system theory, Energy and Buildings, 43 (6) (2011) 1273-1279.

[79] C. Shapiro, S. Puttagunta, D. Owens, Measure Guideline: Heat Pump Water Heaters in New and Existing Homes, in, Steven Winter Associates, Inc., 2012. 
[80] AIL RESEARCH, INC., Nyle heat-pump water heater evaluation final report, 2002.

[81] J.J. Tomlinson, All Pumped Up-New heat pump water heaters consume half the energy of conventional electric-resistance ones, Home Energy, (2002) 30-35.

[82] T. Okamura, Y. Shimoda, Y. Yamaguchi, Y. Yamaguchi, The effectiveness of introducing effective energy saving's measures for households in Japan's residential sector, in: Eleventh International IBPSA Conference, Glasgow, Scotland 2009, pp. 308-315.

[83] A. Ugur, A simple peak shifting DSM (demand-side management) strategy for residential water heaters, Energy, 62 (2013) 435-440.

[84] A.Z. Dalgleish, The development, implementation and performance evaluation of an innovative residential load management system, School of Mechanical Engineering, North-West University 2009.

[85] A.H. Arteconi, N. J.; Polonara, F., State of the art of thermal storage for demand-side management, Applied Energy, 93 (2012) 371-389.

[86] A. Arteconi, N.J. Hewitt, F. Polonara, Domestic demand-side management (DSM): Role of heat pumps and thermal energy storage (TES) systems, Applied Thermal Engineering, 51 (1-2) (2013) 155-165.

[87] R. Rankin, P.G. Rousseau, M. van Eldik, Demand side management for commercial buildings using an inline heat pump water heating methodology, Energy Conversion and Management, 45 (9-10) (2004) 15531563.

[88] T. Ericson, Direct load control of residential water heaters, Energy Policy, 37 (9) (2009) 3502-3512.

[89] K.F. Johnson, A.C. Shedd, Applications of Commercial Heat Pump Water Heaters in Hot, Humid Climates, in: The Eighth Symposium on Improving Building Systems in Hot and Humid Climates, Dallas, TX, 1992. [90] W.P. Bernardi, R.P. Belvins, B.D. Sloane, Examination and life assessment of field-tested heat pump water heaters, in, ENERGY UTILIZATION SYSTEMS, INCORPORATED, Monroeville, Pennsylvania, 1982. [91] TIAX LLC, Design Refinement and Demonstration of a Market-Optimized Residential Heat-Pump Water Heater, 2004.

[92] C.W. Roh, M.S. Kim, Effect of vapor-injection technique on the performance of a cascade heat pump water heater, International Journal of Refrigeration, 38 (1) (2014) 168-177.

[93] M. Jiang, J. Wu, R. Wang, Y. Xu, Research on the control laws of the electronic expansion valve for an air source heat pump water heater, Building and Environment, 46 (10) (2011) 1954-1961.

[94] M. Kim, M.S. Kim, J.D. Chung, Transient thermal behavior of a water heater system driven by a heat pump, International Journal of Refrigeration, 27 (4) (2004) 415-421.

[95] J. Zhang, R.Z. Wang, J.Y. Wu, System optimization and experimental research on air source heat pump water heater, Applied Thermal Engineering, 27 (5-6) (2007) 1029-1035. 
[96] H.W. Jung, H. Kang, W.J. Yoon, Y. Kim, Performance comparison between a single-stage and a cascade multi-functional heat pump for both air heating and hot water supply, International Journal of Refrigeration, 36 (5) (2013) 1431-1441.

[97] X. Xu, Y. Hwang, R. Radermacher, Refrigerant injection for heat pumping/air conditioning systems: Literature review and challenges discussions, International Journal of Refrigeration, 34 (2) (2011) 402-415. [98] Energy 350, Combination Ductless Heat Pump \& Heat Pump Water Heater Lab and Field Tests, Northwest Energy Efficiency Alliance, E15-294 (2015).

[99] A. Kitanovski, U. Plaznik, U. Tomc, A. Poredo, Present and future caloric refrigeration and heat pump Technologies, International Journal of Refrigeration, 57 (2015) 288-298.

[100] Y.L. The, K.T. Ooi, Experimental study of revolving vane (RV) compressor, Applied Thermal Engineering, 29 (2009) 3235-3245.

[101] Y. Tao, H. Lee, Y. Hwang, R. Radermacher, C. Wang, Electrochemical compressor driven metal hydride heat pump, International Journal of Refrigeration, 60 (2015) 278-288.

[102] A.S. Vieira, R.A. Stewart, C.D. Beal, Air source heat pump water heaters in residential buildings in Australia: Identification of key performance parameters, Energy and Buildings, 91 (2015) 148-162. 